\title{
An analysis of haiku teaching discourse: From talking about to doing haiku
}

\author{
Hong-Nguyen (Gwen) Nguyen ${ }^{1}$ and Wolff- Michael Roth ${ }^{2}$ \\ ${ }^{1}$ University of Victoria, Faculty of Education, Canada (ORCID: 0000-0001-9846-5954) \\ ${ }^{2}$ University of Victoria, Faculty of Education, Canada (ORCID: 0000-0001-9344-496X)
}

\begin{abstract}
Haiku have attracted interest among educators and teachers because of their aesthetic, intellectual, and therapeutic possibilities. Teachers whose interest is piqued might turn to online resources as haiku are not yet officially taught in teacher education programs. This paper is designed to investigate the discourses of resources concerning haiku that teachers might find online. Drawing on a discourse analysis, this study reveals two different discourses: (a) a talking about haiku discourse, which includes topics concerning theoretical aspects of haiku; and (b) a talking/doing haiku discourse, which concerns modelling haiku. The latter shows a movement toward an authentic practice in teaching haiku instead of using only a metalanguage approach. Based on the findings, an increased initial focus on the actual doing (talking) haiku is suggested preceding the elaboration of historical and other structural information to enhance its potential benefits.
\end{abstract}

Keywords: Haiku; Discourse; Discourse analysis; Authentic practice; Teaching poetry

Article History: Submitted 8 February 2019; Revised 28 June 2019; Published online 14 August 2019

\section{Introduction}

In recent years interest has grown among teachers, educators, and researchers in using poetry as and for inquiry. In addition to the question, 'What is a good poem?, many studies have raised another concern, 'What is a poem good for?', leading to new forms of knowing about poetry, as well as to new methods in research, poetic inquiry (Faulkner, 2010; Leavy, 2014; Leggo, 2011). For example, poetry has been used as creative and narrative writing for therapeutic engagement, for facilitating reflective learning and teaching, and for fostering empathy and transformation in education (Hojat, 2007; Porter, 2016; Wright, 2005). In addition, poetry as a research method has attracted many teachers and researchers in the field of healthcare and education because of its intellectual, aesthetic, and emotional potential (Galvin, Prendergast, \& Biley, 2016; Romanyshyn, 2014). Poetry helps maximize participation and participative writing in aesthetic ways and evokes the possibilities of the relational, ambiguous, and mysterious presence of a phenomenon (Thomas, Cole, \& Stewart, 2012). Thus, 'perhaps the greatest promise of poetic inquiry is an offer of one way to mediate the shadows of our cultural dream and return home to our embodied, mortal human existence' (Galvin, et al., 2016, p. xiii).

Address of Corresponding Author

Hong-Nguyen (Gwen) Nguyen, University of Victoria, Faculty of Education, Department of Curriculum and Instruction, Victoria, BC, V8P 5C2.

$\triangle$ hongnguyen41@gmail.com

How to cite: Nguyen, H.N., \& Roth, M.W. (2019). An analysis of haiku teaching discourse: From talking about to doing haiku. Journal of Pedagogical Research, 3(3), 113-125. 
Within this trend, the teaching and learning of haiku, a poetic form originating in Japan, has been embraced and applied in diverse educational environments. Educators have included the practice of writing haiku in the curriculum because of its therapeutic benefits (Biley \& ChampneySmith, 2003; Stephenson \& Rosen, 2015). Haiku have also been taught as creative writing to foster empathy in the classroom and to support transformative learning and the use of art in practice (Gair, 2012). Furthermore, haiku have been used as an aesthetic method in human and social research to translate and analyze data so as to capture the depth and intensity of emotions, engagement, and experiences of participants (Prendergast, et al., 2009). Despite this trend, however, haiku are not yet officially taught in teacher education or professional development programs; teachers and educators who are interested in practicing haiku or integrating it in their curriculum might turn to online resources in searching for ways of applying haiku. Yet, those who look for clarification concerning how to teach and learn haiku might (a) become confused by the various teaching practices available in the literature of teaching haiku, and (b) find scant empirical research on haiku-related topics (Wilson, 2010). This study was designed to fill these lacunae by investigating the discourse of haiku through an extensive database focusing on various existing and theoretical ways of teaching/using haiku because learning about how it is approached can then enhance its potential therapeutic benefits.

\subsection{Discourse and Haiku}

The purpose of the paper is to investigate the discourses of haiku used among teachers, educators, and other practitioners. Here, we articulate the notion of discourse and provide background on haiku.

\subsubsection{Discourse or language}

The term discourse frequently is used to indicate 'the special way in which natural language, spoken and written, is used in particular disciplines or by particular communities of practice' (Roth, 2005, p. 317). Discourse is not treated as an abstract linguistic code, but is taken as central to interaction and cognition (Edwards \& Potter, 1992). That is, instead of considering discourse as a theoretical abstraction, we consider discourse as a socio-cultural (cultural-historical) practice that is a topic of study in its own right. Written and verbal text displays how people approach and define certain topics. It shows how language is used to do things and talk about things. In other words, investigating (topicalizing) discourse means studying and understanding different processes or patterns at work. Therefore, uncovering the discourse of haiku promises to help us understand how people casually and routinely use language to talk about and do things with haiku, such as describing, reporting, or accounting for actions.

Discourse, being common to authors and recipients (listeners, readers), inherently is social. Every word in a spoken or written exchange, therefore, is a reality for two and language is consciousness for others and the self (Vygotsky, 1987). Discourse is a cultural possibility situationally mobilized for the purposes at hand. Discourse analysis, therefore, reveals cultural patterns rather than individual characteristics. Rather than considering the internal elements of a speaker or author acting to preserve or maintain a 'self' or self-image, discourse analysis focuses on language as the primary 'reality-constituting resource' (Roth \& Hsu, 2010, p. 302).

This form of analysis constitutes a challenge to the idea that what people make available in their spoken or written text is 'an image of what is going on inside of them, in their hearts and minds' (Willig, 2014, p. 341). Instead, discourse analysis attends to the constitutive and performative properties of language. In use, language is not simply a transparent or neutral system for conveying information; it becomes a means of acting socially. Language also constitutes the topic (content of talk) and analytical objects (actions, constructions, and variability). In sum, discourse analysts concern themselves with forms of discourse that are available publicly to all participants and investigate how people make use of language to constitute both an activity and a topic of talk (Roth, 2008). 


\subsubsection{Haiku - the 5-7-5 structure and the philosophy of doing}

Haiku, a poetic genre using only seventeen syllables divided into three verses (5-7-5), evolved in Japan in the 17th century. It originated in the waka poem (Zizovic \& Toyota, 2012), which features thirty-one syllables in five verses (5-7-5-7-7). During the Heian period in Japan (794-1185), waka appeared in a poetic game, or renga (linked verse), in which a first participant recited the opening verses (5-7-5) and a second participant added the next two verses (7-7). The first link (5-7-5), known as hokku, was crucial because it set the tone and style of language, the mood, and the seasonal context of the whole poem (Cobb, 2013). It was carefully planned in advance so that more spontaneous stanzas could follow. Haiku emerged from hokku and 'gradually developed into a more crystallized form' in Japanese poetry (Zizovic \& Toyota, 2012, p. 33). Despite its brevity, haiku always requires certain features, such as a kigo (a seasonal word) and a kireji (a cutting word); the latter divides the haiku into two parts, usually after the first or the second line (Cobb, 2013). The point of a haiku is implied rather than directly expressed and so haiku have been styled 'the half-said thing' (Cobb, 2013, p. 5). A haiku poet paints a vivid picture, usually in delicate and precise poetic short-hand, and leaves it up to the reader to experience and find his or her own meaning (Nguyen, 2011).

Each haiku represents a direct experience or an instantaneous reflective moment without explication through words (Russel, 2003). The art of haiku has been influenced by Taoism, emphasizing that words cannot ever name the thing (Chten, 1984; Miller, 2008). In the practice of writing haiku, writers learn to reflect in action. This embodies the Japanese philosophy of do embodied in many disciplines, where do means 'the way of,' or 'the method of.' For example, shodo signifies the 'way of calligraphy,' kado, the 'way of flower arrangement,' and aikido, the 'way of unifying with life energy.' 'Do' refers to the 'developmental path followed by the practitioners of a discipline' (Masciotra, Roth, \& Morel, 2007, p. 113). Likewise, the very essence of haiku is doing, describing being at the present moment. Bazzano (2002) says that a haiku poem reveals the world as 'becoming' without any assumption or judgement; within the practice of writing haiku, practitioners learn to write verses that are often simple, authentic, and undramatic - "things happen when they happen, happy, or sorrowful, and that is part of the appeal" (Addiss, 2012, p. 91).

Currently, haiku is widely taught in English-speaking countries and in other languages around the world, especially in language and literature classes (Iida, 2010; Marshall, 2013; Wakan, 2003). Over the past 100 years, 'haiku has gone far beyond its Japanese origins to become a worldwide phenomenon - with the classic poetic form growing and evolving as it has adapted to the needs of the whole range of languages and cultures that have embraced it' (Addiss, 2012, p. i). However, how appropriately to teach, read, and write haiku remains controversial (Blasko \& Merski, 1998; Rielly, 1988).

\section{Research Methods}

\subsection{Data Collection}

For this study, we compiled and examined a collection of 15 videos posted on YouTube over the past ten years describing how to teach/read haiku; we also collected and examined 40 different articles/texts available online from different journals and websites regarding teaching and learning to write haiku. The 15 videos with the most views (all have had more than 1000 viewers in the last ten years) were chosen from more than 14,000 videos related to haiku; the videos lasted from 2 to 30 minutes, constituting a total of 101.09 minutes. These oral texts were either informal tutorials by haiku teachers/learners or academic interviews/talks with poets or professors of poetry/haiku at universities. The 40 additional texts ranged widely from formal instruction appearing on websites on how to teach/read haiku in English to book chapters or peer-reviewed articles regarding haiku. The texts were chosen to represent how haiku have been used in diverse environments in Western education. All of the written texts (a list may be obtained from the 
authors) were combined to form one Word document of some 108,350 words and are line numbered for reference in this paper.

\subsection{Discourse Analysis}

This study analyses the forms of discourse available in haiku-related texts that teachers or educators may encounter when searching for teaching materials online. This investigation is not limited to the content of what is said in those texts. As the 'patterns in language use are always and already cultural,' the content of talk never belongs only to those who produce it. In fact, 'the contents of talk [are] available generalized cultural resources, and what people produce in ... texts [are] nothing more than concrete realizations of these existing ways of talking' (Roth, 2005, p. 354). Here a form of analysis is employed that affords examining a text carefully and identifying ways in which haiku are spoken of and written about - that is, how they are constructed and mediated as a social phenomenon. The form of discourse analysis enables uncovering the ways in which forms of discourse are mobilized and discursive topics are constituted.

Discourse analysis, deriving from discursive psychology, is distinct from discursive sociolinguistics. The latter considers language and linguistic structure per se, while the former considers discourse as a pragmatic means to achieve the purpose at hand (Edwards \& Potter, 1992). From our perspective, the way language is used to sustain common practical purposes frames what and how people can engage in discourse, and concrete discursive acts create both the purpose at hand and the means of attaining it, and, therefore, credible concepts. Moreover, instead of assuming that grammar and other features of language are independent of the purpose of a talk or text, this study takes these to be practical and interactive means of making an activity what it is (Roth, 2008).

\section{Results and Discussion}

\subsection{Talking about Haiku and Talking (doing) Haiku}

Upon examining all texts in our database, we found two forms of discourse. We have named these the talking about haiku discourse and the talking/doing haiku discourse, which makes reference to performing haiku. The talking about haiku discourse includes four discursive topics, which we have labelled the topic about haiku form, the topic regarding the historical dimension of haiku, the topic regarding the comparison between traditional and current haiku, and the topic about the use of haiku. The doing haiku discourse is identified through the deployment of examples that illustrate historical or other structural information, and the teaching by doing.

Table 1 summarizes the topics in our haiku-related texts. The table shows that the topic of form is the most prevalent (appearing in 100\% of our texts), followed by the other topics that evoke the discourse of talking about. The teaching by doing discourse appears more often in oral texts from videos of interviews or short talks $(66.6 \%)$ than it does in haiku-related articles, lessons, or book chapters $(15 \%)$.

Table 1.

A summary of the frequencies of topics from oral and written texts

\begin{tabular}{llcc}
\hline \multirow{2}{*}{ Discourse } & Topics & $\begin{array}{c}\text { Oral text } \\
(\mathrm{N}=15)\end{array}$ & $\begin{array}{c}\text { Written text } \\
(\mathrm{N}=40)\end{array}$ \\
\hline \multirow{4}{*}{ Talking about haiku } & Forms & 15 & 40 \\
\cline { 2 - 4 } & Historical dimension & 13 & 36 \\
\cline { 2 - 4 } & Tension of traditional and current haiku & 13 & 37 \\
\cline { 2 - 4 } & Use of haiku in different contexts & 15 & 34 \\
\hline \multirow{2}{*}{ Talking/doing haiku } & Historical and structural examples & 15 & 40 \\
\cline { 2 - 4 } & Teaching by doing & 10 & 6 \\
\hline
\end{tabular}




\subsection{Talking about Haiku}

The talking about haiku discourse consists of topics concerning the presentation or explanation of haiku. This discourse is mobilized in all texts examined and it appears early in talk or in the beginning parts of each written text. It appears in texts as four discursive topics, namely, the topic about haiku form, the topic about the historical dimension of haiku, the topic about comparison between traditional and current haiku, and the topic about the use of haiku. We demonstrate how each of these topics is mobilized in our database to justify teaching or to clarify the lesson of haiku. We exhibit two short excerpts, either from YouTube video transcripts or from online written texts to demonstrate the use of each topic in different situations. For the purpose of keeping our analysis succinct, we refer to fragments in our analysis by the line numbers in our Word document.

\subsubsection{The form of haiku}

The topic about form of haiku introduces the structure or form of haiku. It is found in all texts in our database. We can observe this topic through the deployment of verbs that denote the forming and phrases that illustrate the requirements of doing haiku. All texts describe haiku as a poetic form with three lines, or with seventeen syllables, or arranged in a 5-7-5 order and with no rhymes. In addition to the limited number of verses or syllables in a haiku, this topic evokes discourse regarding simplicity of language, exactness of expression, objective observation, and direct description. Moreover, the formality topic also explains that haiku has other important features, including elements of nature, a seasonal word, or a subject shift through juxtaposed ideas or images.

All texts present one or more of the characteristics mentioned above. For example, in fragment 1 , the title - a suggestion or invitation for doing haiku - is followed by a series of sentences with the same structure, namely, verbs that describe features and descriptive phrases.

Fragment 1

[i] Let's do haiku.

[ii] Haiku use simple words and keen observations to describe scenes in nature. [iii] Each haiku consists of 17 syllables divided into three lines. [iv] In the English adaptation, the first line contains five syllables; the second line, seven syllables; and the third line, five syllables. [v] Haiku also contain a kigo-a reference to a season of the year.

The invitation, 'Let's do haiku' [i], creates an expectation that instructions or guidelines of haiku structure will follow. Indeed, the deployment of the verbs 'use,' 'consists,' 'contains,' and descriptive phrases, 'a reference to a season of the year' [v], 'simple words,' or 'keen observations' [ii], evokes the discourse regarding the formality of haiku.

Similarly, we can examine a formality discourse in fragment 2, which is a grading checklist used in teaching haiku. In this fragment, if we look at 'Haiku Grading Checklist' as the claim or the belief of how to write a good haiku, then the items listed in the checklist become a resource for the claim, or evidence for the belief. The formality topic here represents a discourse that writing haiku needs to follow certain basic steps or have certain characteristics, such as '3 lines,' 'a pattern of 5-75 syllables,' or 'the poem relates to season.'

Fragment 2

Haiku Grading Checklist Contains 3 lines

Contains a pattern of 5-7-5 syllables

The poem relates to season or how they form

The poem contains all the correct information on seasons or how they form

It contains adverbs and adjectives, and/or descriptive language

Total number of checks 
Percentage
Teacher Comments:

In short, although no words such as 'rules' or 'formality' explicitly appear, texts mobilize the topic of the formality of haiku when presenting ideas regarding teaching haiku. Texts normally describe, present, or introduce the structure or the form of haiku in talking about this form of poetry.

\subsubsection{The historical dimension of haiku}

The historical dimension of haiku topic reflects the presentation or explanation of the historical background of haiku. This topic can be found intertwined with the formality topic. When a text describes the structure of haiku, a further explanation of the history of haiku often follows. However, although the formality topic is employed in all texts, the historical dimension topic does not appear universally. Consider the following excerpt from a talk in our database between two poet laureates. Here, many adverbial time phrases with past tense forms of verbs are used, such as 'in the 17th century,' 'the end of or the beginning of the 18th century,' and 'at the end of the century' [ii], which denotes a pattern, naming a period of time in which haiku were initiated and developed by haiku masters who 'taught poetry' [iii].

Fragment 3

[i] uh I'd like to hear some of course but there's one other thing that intrigued me. [ii] In the introduction you say that all three of these poets living in the 17th century the end of or the beginning of the 18th century beginning and the last one [H: yes], [iii] Issa, that all three taught poetry uh at the end of the century [H: yes] [iv] I was intrigued by that thought that this was an American innovation, the workshop [H: yeah]. [v] so I'm wondering what that meant to them.

[vi] Well, it's a bit complicated to explain, but uh I guess the first thing to say is that haiku as Americans understand it little three-line or 17-syllable poems 5-7-5 um didn't really exist in Japan as an independent entity until the beginning of the 20th century.

The text continues to emphasize the importance of the historical dimension of haiku by stating that a misunderstanding exists among Americans; and by explaining that haiku 'didn't really exist in Japan as an independent entity until the beginning of the 20th century' [vi]. Taken together, these time phrases and verb tenses function in the text as cultural blocks that people make use of in supporting talk about how haiku have evolved to the present form. As well, the repetitive use of these time phrases forms a pattern claiming that talking about haiku or teaching haiku always involves the important work of introducing the history of haiku as of today. In sum, statements with time phrases and words that connect events demonstrate the discourse of the historical dimension of haiku.

\subsubsection{The comparison between traditional and English haiku}

The database provides evidence for a discourse concerning the difference, or tension, between traditional Japanese haiku and the English haiku. Such discourse can be identified through phrases or sentence structures that compare/contrast variations in formats, topics, and inspirations between Japanese and English haiku. For example, in the following segment from an article explaining how to write haiku, the comparison topic is mobilized through the use of phrases, 'in the English adaptation' [ii] or 'in traditional haiku' [iv], which indicates differences between the English adaptation and the original form.

Fragment 4

[i] Each haiku consists of 17 syllables divided into three lines. [ii] In the English adaptation, the first line contains five syllables; the second line, seven syllables; and the third line, five syllables.... [iii] The form calls attention to ideas behind the observations, leading to a moment of sudden insight - the haiku moment. [iv] In traditional haiku, there is often a division between two parts of the poem. [v] A colon or a dash inserted in the poem indicates two contrasting parts and helps draw attention to the thoughts behind the words. [vi] Japanese translations do not always conform to the syllable pattern of 5-7-5. 5 
Many translators emphasize the minimalist nature of the form by using as few words as possible. [vii] In contemporary haiku, as well, more emphasis is given to capturing a moment with precise images than adhering to the syllable count of 5-7-5. [viii] Poet Bruce Lansky (2014) argues, 'The essence of haiku is the way it describes natural phenomena in the fewest number of words. . . [ix] That artistic effect, to me, is much more important than the number of syllables used.

Here, the text makes use of compare/contrast phrases to present the idea that the form of English haiku is different from the original form: the English form utilizes a five-seven-five syllable structure [i], whereas the traditional form uses two contrasting parts within a poem. The text relies on adverbial clauses followed by statements to show the difference between the old and the new haiku in form; the comparison discourse is also further confirmed in this fragment in sentences [vi] to [ix], with the repetition of comparing/contrasting structures or words, such as 'not always conform to the syllable pattern of 5-7-5' [vi], or 'using as few words as possible' [vi], or 'more emphasis is given to capturing a moment with precise images than adhering to the syllable count of 5-7-5' [vii], or 'much more important than the number of syllables used' [ix].

Fragment 3 demonstrates how speakers mobilize the comparison topic when talking about haiku. Here, in addition to the formality and historical dimension topic, the talking about haiku discourse utilizes a comparison. In finding ways to teach or further explain haiku, the text draws on comparison structures to describe the difference in haiku as 'American[s] understand it' [vi] and those that are 'very Japanese' [vi]. The employment of those linguistic devices creates a discourse regarding a contrast between original Japanese haiku, which has to do with courts and Japan, and current haiku, which is misunderstood as the 5-7-5 form. These features, adverbial phrases with compare and contrast grammatical structures, show that the text or talk related to haiku always includes a theoretical presentation on how haiku in English are different from original haiku. Drawing on those linguistic structures, people support their belief that it is worthwhile to contrast the change while teaching haiku.

\subsubsection{The use of haiku in different contexts}

Another topic within the discourse of talking about haiku concerns the use of haiku in different contexts. This topic indicates that the haiku form is taught/learned for certain purposes. In presenting, teaching, or talking about haiku, texts illustrate or emphasize haiku as a teaching tool, or as subordinate to other activities. For example, fragment 5 is taken from an article on how to teach haiku writing to non-English speakers.

Fragment 5

[i] Haiku is not simply a means for private self-expression; composing and producing haiku is a communicative act that builds a writer-reader interaction. [ii] Haiku entertains readers, and it is the readers who judge the quality of haiku (Minagawa 2007). [iii] Therefore, composing haiku allows L2 writers to become sensitive to the writer-reader relationship, a fact that matches Japanese scholars' theories of using haiku in the classroom, where it plays an important role in CLT (Suzuki et al., 2003).

Here, haiku is said to entertain, which has the consequence that the reader evaluates the poem. The discourse deploys the implicative to state that learning to write haiku helps learners understand the reader-writer relationship [iii]. A series of statements about the value or effects of haiku precedes this implicative [i, ii]. In legitimating the idea of how to teach haiku, the text makes reference to the use repertoire, evoking discourse about the use of haiku. Furthermore, we observe the repetition of the syntactical structure in which haiku is the subject of the sentence and is followed by verbs denoting the effects, the use, or the purpose; for example, in 'haiku entertains . . .' [ii] or 'composing haiku allows ...' or 'it plays an important role in' or 'composing haiku lets ...' [iii]. This linguistic feature helps the reader to know that the topic regarding the usefulness or power of haiku or writing haiku is emphasized in the text. That is, the repetition of the structure 'haiku + cause/effect verb' is the resource for the formation of the discourse of talking about the use of haiku. 


\subsection{Talking/doing haiku}

Together with the talking about haiku discourse, we also found discourse regarding doing or performing haiku. If the talking about haiku discourse emphasizes the theoretical presentation or description of haiku, the talking/doing haiku discourse refers to the practice, the action of writing haiku. We can also think of this discourse as one that relates to the actions and performances practiced in the haiku class or in real life. In talking/doing haiku discourse, we may distinguish between the deployment of examples that illustrate historical and other structural information and the creation of text that teaches haiku by means of haiku.

\subsubsection{Historical examples}

The modelling topic demonstrates the action of providing examples to further explain haiku. In our database, speakers often recite haiku written by traditional Japanese poets or by students, after introductory verbs, phrases, or sentences identifying an illustration. For example, in fragment 6, along with the topic about form, the text includes signpost language that evokes the topic of giving examples or illustrations, such as 'as in' [iii], 'like' [iii], 'for example' [iv], and 'note' [v].

Fragment 6

[i] Include a seasonal reference. [ii] A reference to the season or changing of the seasons, referred to in Japanese as kigo, is an essential element of haiku. [iii] The reference may be obvious, as in using a word like 'spring' or 'autumn' to indicate the season, or it might be subtler. [iv] For example, mentioning wisteria, which flower during the summer, can subtly indicate the season. [v] Note the kigo in this poem by Fukuda Chiyo-ni:

[vi] morning glory!

the well bucket-entangled,

I ask for water

In addition, we observe the appearance of the haiku example [vi], used to document the appearance of the kigo. Clearly, a different haiku could have been presented, in which case this fragment could lead to a different perspective and not be as coherent. In this use, the poem has an exemplary function: it does 'seasonal reference' [i] well enough so that the audience may recognize it. In short, the use of signpost language and the work of displaying and explaining the poem shows that people present examples simultaneously with formulating the topic of form.

Teaching by Doing
Haiku may be taught by put
form:
[iv]Composing haiku
Lets you open special gates:
Exploring yourself

If we read this as 'Composing haiku: Lets you open special gates, exploring yourself,' it is a normal statement. However, here this statement appears in the form of 5-7-5 or 17 syllables and is intentionally broken into three separate lines. That is, this haiku appears in the text as an example of how practice with this 5-7-5 form can help. This way of presenting the example is intentional and evokes the topic of the use or effects of haiku in specific contexts. At the same time, it also illustrates that people teach haiku by creating a poem with the structure of haiku or evoking the use of haiku. In sum, when discussing how to teach haiku, texts call on discourse of demonstration and modelling to follow up or support the discourse of the talking about haiku.

Audiences also are invited to participate in the creative process of writing haiku in other ways. In fragment 7 , we can observe run-on phrases/sentences that present interwoven demonstrations and explanations and that never seem complete, such as 'as if I wrote,' 'and then which,' 'suppose your next two lines were,' 'so it would go,' and 'the third poem would then take.' We also note different, improvised haiku verses continuously appearing throughout the text, which functions as 
a reminder that haiku writing is a 'call and response form' [i]. The pattern of run-on phrases/sentences and improvised haiku verses creates a feeling that the text is calling for a work of co-imagination, understanding, and co-creating. In general, these linguistic features show how the speakers map the talk about haiku with the work of modelling.

Fragment 7

$\mathrm{H}$ : [i] It began really centuries earlier in which they would take the typical five-line poem and um um they and improvise it in a call and response form, as if I wrote "we're sitting in the studio under the television light" um "it's an October afternoon outside" those three lines you had to write two more lines to finish the poem. (20.58) [I: ah ha!] [ii] And then which-you can imagine a couple of renaissance poets or a couple of American poets - as the form developed, suppose your next two lines were um ah ah "there was broken light on the lake when the sun came up." [iii] So it would go "we're sitting in a television studio under the lights outside it's a late March afternoon there was broken light on the lake when the sun came up."

If we look back at fragment 5 or 6 , we can see that with separate sentences in a clear, written organization, the text creates the impression that what is being described is straight forward, and that the speaker or writer is clear about the message he or she wants to convey. However, in fragment 7, the talk is not only characterized by run-on sentences, filler words, pauses and hesitation, but also by the use of qualifiers and hedges such as 'as if' or 'suppose' and the subjunctive 'would,' which shows that the speaker does not have a clear sense of his or her direction.

A clear difference is apparent between the oral text (fragment 7 ) and written text (fragments 5 and 6). In both cases, the text shows the work of modelling haiku through the deployment of signpost language and haiku verses as examples. However, the oral text clearly presents a discourse of teaching by doing with characteristic features, such as incompleteness, uncertainty, and lengthiness. In short, we find this modelling discourse and its function in the text similar to the discourse of coaches when demonstrating and explaining to students (Schön, 1987). In a practicum, a coach cannot be certain about what students seek to learn; thus, a coach uses discourse combining description and demonstration.

\subsection{Between Information Transfer and Authentic Practice}

This study was designed to analyze the discourse of haiku that teachers may find when searching for materials that might assist them to instruct students in this poetic form. Our analysis reveals the presence and a distinction between the talking about haiku discourse and the doing haiku discourse. These two forms of discourse are different both in content (or the topics) and in the manner in which the topics are presented and used. Whereas the topics found in the talking about haiku discourse are formed so as to present and describe theoretical aspects of haiku, the modelling topic is composed of giving examples or performing or improvising haiku. The talking about haiku discourse characterizes a clear, well-prepared, and well-organized style of presentation with respect to structure, historical dimension, the differences between traditional and western haiku, and the application of this form. The talking/doing haiku discourse, on the other hand, indicates a performance dimension to haiku, which may be exemplified or modelled in improvisation. While the talking about haiku discourse is identified with more themes and is prevalent in all texts $(86.6 \%-100 \%)$, the doing haiku discourse appears more often in oral texts (Table 1.1). In comparing oral texts from interviews or short talks with written texts, we find that people also tend to list historical or structural examples of haiku $(100 \%)$ rather than teach by doing ( $66 \%$ and $15 \%$ in oral and written texts, respectively).

\subsubsection{Talking about vs talking/doing haiku}

The two parallel forms of discourse are relevant to the literature of teaching poetry as they reflect the dichotomy between talking about and doing or authentic practice. Talking about refers to the transfer of abstract and decontextualized concepts, which makes up the concern of traditional 
classrooms; authentic practice is a form of learning/teaching embodied or situated in socially, culturally, and historically constructed activity by both teachers and learners (Brown, Collins, \& Duguid , 1989; Schön, 1987). The study shows that the way the discourses of haiku are constituted in haiku-related texts is similar, if not identical, to a pre-set unit-lesson plan of any teacher presenting material in the classroom. A teacher starts with a brief introduction to the concept, perhaps including his or her personal point of view. Then he or she will solicit the knowledge (schemata) of the learner when comparing and contrasting what is already known with what might be new. Following this are examples, illustrations, and guided practice.

Research has shown a strong advocacy for authentic practice, that is, for learning/teaching by doing (Collins, Brown, \& Newman, 1989; Elliott, 1994) bringing authentic activities into the classroom enables knowledge to be 'socially constructed through negotiations among present and past members' (Brown, et al., 1989, p. 34). Despite many efforts from teachers to apply different teaching methods, formal school activities still remain detached from practice (Martin, 2012) and teaching practices in various specialty fields, therefore, are divided between talking the talk and doing the talk (authentic practice, walking the walk) (Roth, 2015). The present analysis shows these two distinctive discourses in haiku-related materials and confirms that the talking about haiku discourse is still dominant as it is strongly developed throughout all forms of oral and written texts $(100 \%)$, while the teaching by doing discourse can be found in only $15 \%$ of the written texts. This, indeed, resonates with other studies in poetry education (Farber, 2015; Gooda, 2016). From traditional to modern methods - such as metalanguage instruction (Wilson \& Myhill, 2012; Van Lier, 1998), reader response (Rosenblatt, 1938), and textual and contextual approaches (Mattison, 2010)-teachers still share misinformed ideas about what makes a good poem and, thus, mistakenly assume that writing poems and teaching learners to write poems is beyond their ability (Brannon, 2012; Linaberger, 2004).

Our finding articulates that teaching haiku normally relies on formal and well-organized presentation and explanation of the theoretical aspects of haiku, such as its form, its use, and its historical background. The actual practice of haiku appears as an appendix.

\subsubsection{Towards doing haiku in teaching haiku}

We can find different viewpoints regarding the discourses of talking about and of doing. For example, some theories suggest that the discourse of doing is not any closer to practice than is the discourse of talking about (Bourdieu, 1990); others maintain that the discourse of practitioners engaged in actual practice is different from the discourse of theoreticians (Schön, 1987). Whatever viewpoint may be taken, one of the most important points of our analysis is that teachers utilize a combination of two discourses, talking about and modelling. The question that teachers/educators might have at this point is 'So what?' Suppose the discourse of doing reflects the actual practice of teachers or practitioners, what could a teacher do to enact authentic practice in teaching haiku?'

The present findings suggest reconfiguring the way in which teachers might teach/learn haiku. It might be impossible to eradicate any topics or forms of discourse through instruction because language is a tool for social action (Roth, 2015). That is, the discursive topics of haiku found in our database both express or represent the reality of teaching/learning haiku and uncover how language is used universally to constitute, maintain, and reconstitute any talk or text related to haiku. Educators may indeed begin with the practice and discourse of doing haiku before expanding on the formal topics about haiku. Authentic practice does not mean discarding all teaching approaches that embrace talking about. However, haiku may be taught in a way that encourages more demonstration, modelling, and improvisation from both teachers and learners. Haiku may be taught through workshops in which participants learn to write haiku in pairs or groups or in the form of a social 'call and response' activity - a haiku gathering-as in the beginning of haiku (Hass, 1994).

It has been suggested that instructions and even demonstration inherently are 'ambiguous, strange, incongruent with the listener's understandings' (Schön, 1987, p. 111). What an instruction 
(or demonstration) really means can be found only in attempts of following it and finding the pertinence of the description in one's own action (Suchman, 2007). This allows teachers and learners to be aware of messiness, gaps, or ambiguity as might appear in a writing haiku together workshop. Writing haiku together may lead to recreating the world represented in the text, because it affords the equal participation of 'the reality reflected in the text, the authors creating the text, the performers of the text (if they exist) and finally the listeners or readers who recreate and in so doing renew the text' (Bakhtin, 1981, p. 253).

\section{Conclusion}

The present study shows that haiku are approached and taught in a particular sequence: (a) introducing haiku structure, (b) exploring further the historical dimension of haiku, (c) explaining the tension between traditional haiku and current haiku, (d) emphasizing the application of haiku, and (e) modelling and providing examples. These topics make evident that the production of haiku-related texts constitutes a new life for haiku, just as other cultural forms that are imported or exported into a new historical social situation renew their lives. The haiku allows itself to transform or to be transformed because no other options arise in moving from one culture to another. Teaching haiku cannot ever be the business of talking about a 5-7-5 structure or its history. If the essence of haiku is in the doing, as maintained in Japanese culture, and if writing haiku brings teachers therapeutic, aesthetic, and intellectual benefits, then teaching haiku might be improved if it were organized as a social game/activity, as it used to be. In such a teaching practice, we would then become aware of the flexibility of the practice and that we live and (re)create haiku during the process of expanding its discourse of doing.

\section{References}

Addiss, S. (2012). The art of haiku: Its history through poems and paintings by Japanese masters. Boston: Shambhala.

Bakhtin, M. (1981). The dialogic imagination. Austin: University of Texas Press.

Bazzano, M. (2002). Zen poems. Kansas City, Kan: Andrews Mcmeel Publishing.

Blasko, D. G., \& Merski, D. W. (1998). Haiku poetry and metaphorical thought: An invitation to interdisciplinary study. Creative Research Journal, 11(1), 39-46.

Biley, F. C., \& Champney-Smith, J. (2003). Attempting to say something without saying it . . : writing haiku in health care education. Journal of Medical Ethics: Medical Humanities, 29, 39-42.

Bogina, M. A., \& Roberts, B. R. (2005). The use of haiku and portfolio entry to teach the change of seasons. Journal of Geoscience Education, 53(5), 559-562.

Bourdieu, P. (1990). In other words: Essays towards a reflexive sociology. Stanford: Stanford University Press.

Brannon, A. (2012). Love that poem! Using imitation to teach poetry. The English Journal, 102(2), 51-56.

Britton, J. (1982). Reading and writing poetry. In G. M. Pradl (Ed.), Prospect and retrospect: Selected essays of James Britton (pp. 9-19). London: Heinemann.

Brown, J. S., Collins, A., \& Duguid, P. (1989). Situated cognition and the culture of learning. Educational Researcher, 18(1), 32-42.

Chten, E. T. (1984). The conception of language and the use of paradox in Buddhism and Taoism. Journal of Chinese Philosophy, 11, 375-399.

Cobb, D. (2013). Haiku. New York: Overlook Press.

Edwards, D., \& Potter, J. (1992). Discursive psychology. London: Sage.

Elliott, J. (1994). Research on teachers' knowledge and action research. Educational Action Research, 2(1), 133140

Farber, J. (2015). On not betraying poetry. Pedagogy: Critical Approaches to Teaching Literature, Language, Composition, and Culture, 15(2), 213-232. doi 10.1215/15314200-2844985.

Faulkner, S. (2010). Poetry as method. Walnut Creek, CA: Left Coast Press.

Gair, S. (2012). Haiku as a creative writing approach to explore empathy with social work students: A classroom-cased inquiry. Journal of Poetry Therapy, 25(2), 69-82. doi:10.1080/08893675.2012.680717 
Galvin, K. T., Prendergast, M., \& Biley, F. C. (2016). Poetic inquiry II: Seeing, caring, understanding: Using poetry as and for inquiry. Rotterdam: Sense. doi:10.1007/978-94-6300-316-2

Gooda, T. (2016). If we teach writing, we should write. English in Education, 50(3), 270-279.

Hass, R. (1994). The essential haiku: Versions of Basho, Buson, and Issa. Hopewell, NJ: Ecco.

Henderson, H. G. (1958). An introduction to haiku: An anthology of poems and poets from Basho to Shiki. Garden City: Doubleday.

Hodges, G. C. (2016). Becoming poetry teachers: Studying poems through choral reading. Changing English, 23(4), 375-386. doi: 10.1080/1358684x.2016.1203246

Hojat, M. (2007). Empathy in patient care. New York: Springer.

Hudson, Z. (2013). Haiku in the classroom: more than counting syllables. English Journal, 102(6), 54-57.

Iida, A. (2010). Developing voice by composing haiku: A social-expressivist approach for teaching haiku writing in EFL contexts. English Teaching Forum, 1, 28-34. Http://americanenglish.state.gov/files/ae/resource_files/10-48-1-e.pdf

Leavy, P. (2014). Method meets art. New York: Greenwood.

Leggo, C. (2008). Astonishing silence: Knowing in poetry. In J. G. Knowles \& A. Cole (Eds.), Sage handbook of the arts in qualitative research (pp. 165-174). Thousand Oaks, CA: Sage.

Leggo, C. (2011). What is a poem good for/14 possibilities. Journal of Artistic and Creative Education , 5(1), 3258.

Linaberger, M. (2004). Poetry top 10: A foolproof formula for teaching poetry. The Reading Teacher, 58(4), 366372.

Marshall, I. (2013). Stalking the gaps: The biopoetics of haiku. Mosaic: A Journal for the Interdisciplinary Study of Literature, 46(4), 91-107.

Martin, J. (2012). Toward authentic electronic music in the curriculum: Connecting teaching to current compositional practices. International Journal of Music Education, 30(2), 120-132.

Masciotra, D., Roth, W-M., Morel, D. (2007). Enaction: Toward a Zen mind in learning and teaching. Rotterdam: Sense.

Mattison, J. (2010). Teaching poetry: Introducing a contextual and textual approach to undergraduate students. Porta Linguarum, 16, 33-47.

Miller, J. (2008). Daoism: A beginner's guide. Oxford: Oneword.

Nguyen, H. (2011). The haiku approach for an ideal EFL literature class in Vietnam. Saarbrucken: Lambert.

Porter, L.A. (2016). Unnamed moments: Transformation and the doing and making of trauma therapy practices. In K. T. Galvin \& M. Prendergast (Eds.), Poetic inquiry II: Seeing, caring, understanding (pp. 255-272). Sense: Rotterdam.

Prendergast, M., Gouzouasis, P., Leggo, C., \& Irwin, R. L. (2009). A haiku suite: The importance of music making in the lives of secondary school students. Music Education Research, 11(3), 303-317. Doi:10.1080/14613800903144262

Prendergast, M., \& Leggo, C. (2007). Astonishing wonder: Spirituality and poetry in educational research. In L. Bresler (Ed.), International handbook of research in arts education (pp. 1459-1480). New York: Springer.

Prendergast, M., Leggo, C., \& Sameshima, P. (2009). Poetic inquiry: special issue. Educational Insights, 13(3). Retrieved December 17 2017, from www.educationalinsights.ca

Pirrie, J. (1994). On common ground: A programme for teaching poetry. Godalming, UK: World Wide Fund for Nature.

Romanyshyn, R. D. (2014). Leaning toward the poet: Eavesdropping on the poetry of everyday life. Bloomington, IN: Iuniverse.

Rielly, E. J. (1988). Reading and writing haiku in the classroom. Children's Literature Association Quarterly, 13(3), 111-114.

Rosen, M. (1989). Did I hear you write? London: André Deutsch.

Rosenblatt, L. M. (1938). Literature as exploration. New York: Modern Language Association.

Roth, W-M. (2005). Doing qualitative research: Praxis of method. Rotterdam: Sense.

Roth, W-M. (2008). The nature of scientific conceptions: A discursive psychology perspective. Educational Research Review, 3, 30-50

Roth, W-M. (2013). Toward a post-constructivist ethics in/of teaching and learning. Pedagogies: An International Journal, 8, 103-125.

Roth, W-M. (2015). Rigor in qualitative data analysis. Rotterdam: Sense.

Roth, W-M., \& Hsu, P-L. (2010). Analyzing communication: Praxis of method. Rotterdam: Sense. 
Russell, B.D. (2003). Reaching haiku's pedagogical nature. In E. Hasebe-Ludt and W.Hurren (ed.), Curriculum intertext: Place/language/pedagogy (pp. 93-102). New York: Peter Lang.

Stephenson, K., \& Rosen, D. H. (2015). Haiku and healing: An empirical study of poetry writing as therapeutic and creative intervention. Empirical Studies of the Arts, 33(1), 36-60.

Suchman, L. (2007). Human-machine reconfigurations: Plans and situated actions. Cambridge: Cambridge University Press.

Thomas, S., Cole, A. \& Stewart, S. (eds.) (2012). The art of poetic inquiry. Big Tancook Island, NS: Backalong.

Toyota, J., Hallonsten, P., \& Schepetunina, M. (2012). Sense of emptiness: An interdisciplinary approach. Cambridge: Cambridge Scholars.

Ueda, M. (1967). Literary and art theories in Japan. Cleveland: Western Reserve University.

Van Lier, L. (1998). The relationship between consciousness, interaction and language learning. Language Awareness, 7(2-3), 128-145.

Vygotsky, L. S. (1987). The collected works of L. S. Vygotsky, vol. 1. New York: Springer.

Wakan, N. B. (2003). Haiku-writing: Learning from the pine. Green Teacher, 72, 13.

Wetherell, M., \& Potter, J. (1988). Discourse analysis and the identification of interpretative repertoires. In A. Antaki (ed.), Analysing everyday explanation: a casebook of methods (pp. 168-183). Newbury Park, CA: Sage.

Willig, C. (2014). Discourse and discourse analysis. In U. Flick (Ed.), The SAGE Handbook of Qualitative Analysis (341-354). London: Sage.

Wilson, A. C. (2010). Teachers' conceptualisations of the intuitive and the intentional in poetry composition. English Teaching: Practice and Critique, 9(3), 53-74.

Wilson, A., \& Myhill, D. A. (2012). Ways with words: Teachers' personal epistemologies of the role of metalanguage in the teaching of poetry writing. Language and Education, 26(6), 553-568.

Wright, J. (2005). Writing therapy in brief workplace counseling: Collaborative writing as inquiry. Counseling and Psychotherapy Research, 5(2), 111-119. doi:10.1080/17441690500211114

Yasuda, K. (1957). The Japanese haiku: Its essential nature, history, and possibilities in English, with selected examples. Rutland, VT: Tuttle.

Zizovic, S. V., \& Toyota, J. (2012). Emptiness in haiku poetry. Cambridge: Cambridge Scholars. 